\title{
Teach More in Less Time: Introduction to the Special Section on Direct Instruction
}

\author{
William L. Heward $^{1}$ • Janet S. Twyman ${ }^{2}$ \\ Published online: 11 August 2021 \\ (C) Association for Behavior Analysis International 2021
}

An internet search of "direct instruction" yields hundreds of definitions, many of which read like this: A teacher-directed teaching method in which the teacher stands in front of a classroom and uses lectures or demonstrations to present academic content to students. In stark contrast is Direct Instruction, with a capitalized D and I.

Direct Instruction (DI) is a powerful teaching system that combines logical analysis of the content students are to learn, thoughtful selection and sequencing of instructional examples, clear communication between teacher and student, high rates of student engagement, reinforcement and corrective feedback, judicious review, and practice to mastery. The DI model was created by Siegfried Engelmann and Wesley Becker at the University of Illinois in the 1960s and further developed by Engelmann, Doug Carnine, Ed Kame'enui, Jerry Silbert, and others at the University of Oregon.

This special section was kick-started by a symposium at the Association for Behavior Analysis International's 2020annual convention titled Design and Delivery Features of Direct Instruction That You Didn't Know You Didn't Know, and Didn't Know You Needed. Articles describe critical features of DI and how behavior analysts can incorporate DI into their practice.

The September issue of Perspectives on Behavior Science (PoBS) also includes a special section on DI (Heward \& Twyman, 2021). Articles in the PoBS special section review Engelmann's achievements as a pioneering scientist, examine the DI research base, and explore how the DI model and theory of instruction are harmonious with behavior analysis.

William L. Heward

heward.1@osu.edu

Janet S. Twyman

jstwyman@gmail.com

1 The Ohio State University, Columbus, OH, USA

2 blast, Cottonwood, AZ, USA

\section{The Genius Behind Direct Instruction}

Human capacity to learn is not fixed in any ordinary sense. It is not fixed in terms of the responses it will produce; it is not fixed in terms of absolute level of knowledge it will achieve.

—Siegfried "Zig" Engelmann

Siegfried Engelmann devoted his life to designing instructional programs that accelerate children's learning. He was especially concerned with providing effective instruction for at-risk children, particularly children of poverty (Engelmann, 2007), and was convinced that given the right instruction, all children could learn. More than a half century of research evidence shows he was right (Stockard et al., 2010). Engelmann's discoveries of how to teach more in less time are of paramount significance and no less groundbreaking than Lovaas's demonstrations of how systematic, intensive instruction could improve the lives of children with autism.

In 1992, Engelmann discussed the state of educational practice with doctoral students in special education and applied behavior analysis at The Ohio State University. A transcript of that discussion provided the content for "In His Own Words: Siegfried "Zig" Engelmann Talks About What's Wrong With Education and How to Fix It" by Bill Heward, Jonathan Kimball, Kelly Heckaman, and James Dunne. Engelmann gave his no-holds-barred opinion on issues such as developmental theory, child-centered approaches, school reform, the media and education, grouping learners for instruction, and the relationship between DI and behavior theory.

\section{Teach More in Less Time With DI Principles and Procedures}

Six articles in this special section suggest how behavior analysts can use and adopt DI instructional design features and presentation methods in their practice. 
A first-time observer of a well-taught DI lesson is struck by the high-energy level: the rapid pacing, the teacher's verbal and visual signals, and students' choral responses stand out readily from typical teaching methods. Each of these more evident elements of DI plays an important role in students' learning. The casual observer, however, is seldom aware of the sophisticated instructional design at the foundation of DI. A series of three articles takes us inside DI to see how lessons are designed.

In "Features of Direct Instruction: Content Analysis," Tim Slocum and Kristen Rolf explain the role of content analysis in developing DI programs and provide a brief sketch of general methods for conducting a content analysis. To illustrate how effective content analysis works, they share examples in five content domains: spelling, basic arithmetic facts, Earth science, basic language, and narrative language.

To prevent students from learning misrules because of the way concepts are introduced (e.g., triangles are blue, the numerator is always less than the denominator), instructional examples must be selected and sequenced to avoid ambiguity and yield maximum generalization to untaught examples. In "Creating the Components for Teaching Concepts," Kent Johnson and Andrew Bulla outline the steps for developing instructional materials for teaching a concept in any curricular domain. To learn the limits or boundaries of a concept, students respond to examples and nonexamples that are similar to one another except for the critical feature that makes them different. To learn the range of a concept, students identify examples that differ from one another as much as possible yet still illustrate the concept.

Building on the two previous articles, "You Have the Big Idea, Concept, and Some Examples . . Now What?” by Janet Twyman and Adam Hockman shows the utility and importance of considering Engelmann and Carnine's (1991) principles of juxtaposition when teaching a new discrimination or a set of related stimuli (i.e., concept teaching). What they present in the article (and encourage readers to practice) is just the beginning of what it takes to consider logical and researchdemonstrated strategies as part of one's efforts to improve student learning.

Once a lesson is designed, it has to be delivered. "Features of Direct Instruction: Interactive Lessons" by Rolf and Slocum describes the features of DI lesson presentation that maximize student learning: instructional formats that specify the interactions between teacher and student, flexible skillsbased groupings, active student responding, responsive interactions between students and teachers, ongoing data-based decisions, and mastery teaching.

As the previous articles illustrate, examples are essential in learning something new. Fortunately, this special section provides those as well. In "Ten Instructional Design Efforts to
Help Behavior Analysts Take Up the Torch of Direct Instruction," Trina Spencer shows how the DI model and technology are transferrable and applicable to behavioranalytic practice. The article features a detailed planning guide showing behavior analysts how to put the power of DI into practice to establish generative repertoires efficiently, regardless of the population they serve or the repertoires they build. A case example illustrates how DI's instructional design and instructional delivery strategies were incorporated into a program for teaching narrative language skills to children (Spencer \& Petersen, 2020).

In "Guidelines for Facilitating Direct Instruction of Generalized Social Behavior," Terrance Scott and Erick Dubuque describe how practitioners can use general case programming (GCP; Horner et al., 1982). Based on DI principles of instructional design, GCP is a systematic strategy and set of techniques for identifying the full range of relevant stimulus variations and response requirements learners must navigate to perform successfully in novel environments. Scott and Dubuque provide guidelines and a case example of how to select and sequence instructional examples most likely to produce maximum generalization to untaught situations.

\section{Teacher Training and Implementation: Reports From the Field}

Two articles in this special section detail efforts to train practitioners to use DI or parents to implement explicit instruction techniques. "Adventures in Direct Instruction Implementation: The Devil Is in the Details" by Joel Vidovic, Mary Cornell, Sarah Frampton, and Alice Shillingsburg tells the story of how the administrators, teachers, and paraprofessionals at a public charter school serving students with autism worked together over a period of 5 years to make DI the schools' primary form of instruction. Improved reading scores were obtained for 67 students who participated in a DI reading program for at least 2 years, with some students demonstrating greatly accelerated rates of learning. The article includes a lesson plan for training teachers to use choral responding and a procedural fidelity checklist for assessing teachers' implementation of DI lessons.

"Teaching Future School Personnel to Train Parents to Implement Explicit Instruction Interventions" by Sara Kupzyk and Zachary LaBrot describes how a universitybased academic assessment and intervention clinic trains future school personnel to support parents' use of explicit instruction strategies and tactics (e.g., brisk pace, frequent student responding, immediate feedback) during home-based tutoring sessions. To illustrate the process, the authors provide a case example of how a student trained the mother of a 17- 
year-old male to use a model-lead-test procedure to improve her son's early literacy skills.

\section{Acknowledgments}

This special section is the direct outcome of the contributions and collaboration of many. Jonathan Tarbox, the editor in chief of Behavior Analysis in Practice, approved our proposal for this special section and helped get things rolling. Current editor Stephanie Peterson was equally supportive and guided the project to completion.

We give a special tip of the cap to Kurt Engelmann and Bryan Wickman at the National Institute for Direct Instruction (www.nifdi.org) for sharing their knowledge and providing several figures that appear in the articles.

We thank all of the authors who responded to the call for papers. This special section is the product of their expertise and passion for effective instruction. Many fine papers were submitted, and we are pleased to present you with these selected few.

We are especially grateful to the scholars, behavior analysts, and educators who reviewed the submissions, who are listed at the end of this article. The reviewers' expertise and insights improved each submission (some that will be published elsewhere) and helped us determine those most deserving of inclusion in this special section.

\section{Reviewers for the Special Section on Direct Instruction}

Sheila R. Alber-Morgan, The Ohio State University

Sara Bicard, Auburn University, Montgomery

Vivian I. Correa, University of North Carolina, Charlotte

Douglas A. Johnson, Western Michigan University

Amanda Kelly, Breakthrough Behavior
Martin Kozloff, University of North Carolina, Wilmington Amanda P. Laprime, University of Rochester Medical Center Lawrence Maheady, SUNY, Buffalo State

Nancy E. Marchand Martella, Purdue University

Corrine M. Murphy, Western Kentucky University

Sarah Pinkelman, Utah State University

Joanne Robbins, Morningside Academy

Mary R. Sawyer, The Aubrey Daniels Institute

Susan M. Silvestri, QSAC Bronx Preschool and School

Timothy A. Slocum, Utah State University

Melinda Sota, Learning A-Z

Katie Wolfe, University of South Carolina

Charles L. Wood, University of North Carolina, Charlotte

\section{References}

Engelmann, S. (2007). Teaching needy kids in our backward system: 42 years of trying. ADI Press.

Engelmann, S., \& Carnine, D. W. (1991). Theory of instruction: Principles and applications (Rev. ed.). ADI Press.

Heward, W. L., \& Twyman, J. S. (2021). Special section on Direct Instruction. Perspectives on Behavior Science. Advance online publication.

Horner, R. H., Sprague, J., \& Wilcox, B. (1982). General case programming for community activities. In B. Wilcox \& G. T. Bellamy (Eds.), Design of high school programs for severely handicapped students (pp. 61-98). Paul H. Brookes Publishing.

Spencer, T. D., \& Petersen, D. B. (2020). Narrative intervention: Principles to practice. Language, Speech, and Hearing Services in Schools, 51(4), 1081-1096. https://doi.org/10.1044/2020_LSHSS20-00015.

Stockard, J., Wood, T. W., Coughlin, C., \& Rasplica Khoury, C. (2010). The effectiveness of Direct Instruction curricula: A meta-analysis of a half century of research. Review of Educational Research, 88(4), 479-507.

Publisher's Note Springer Nature remains neutral with regard to jurisdictional claims in published maps and institutional affiliations. 